\title{
university
of the arts
london
}

\begin{tabular}{|l|l|}
\hline Title & Being in Analysis: On the Intimate Art of Transference \\
\hline Type & Article \\
\hline URL & https://ualresearchonline.arts.ac.uk/id/eprint/11662/ \\
\hline Date & 2018 \\
\hline Citation & $\begin{array}{l}\text { Morra, Joanne (2018) Being in Analysis: On the Intimate } \\
\text { Art of Transference. Journal of Visual Art Practice, 16 (3). } \\
\text { pp. 163-184. ISSN 1758-9185 }\end{array}$ \\
\hline Creators & Morra, Joanne \\
\hline
\end{tabular}

\section{Usage Guidelines}

Please refer to usage guidelines at

http://ualresearchonline.arts.ac.uk/policies.html or alternatively contact ualresearchonline@arts.ac.uk.

License: Creative Commons Attribution Non-commercial No Derivatives

Unless otherwise stated, copyright owned by the author 


\section{Being in Analysis: On the Intimate Art of Transference}

Joanne Morra

This article will be published in Journal of Visual Art Practice December 2017.

Abstract: In this article the author considers psychoanalytic transference in the context of contemporary art. The author focuses on the work of artists who have been in psychoanalysis and have put this personal material to use within their creative practice, and argues that these artworks enact the experience of being in analysis. Using an expanded understanding of transference wherein the fantasy and reality experienced in the 'here and now' of the consulting room is transposed onto sites of cultural production, the author considers the very real and often disruptive emotional and psychological affects that are a part of the viewer's experience of these artworks. In this article, the author asks: When we are with such work, what do we experience? How might we respond and engage with such intimate work? What is being required of us as viewers? Are we being invited to participate in a form of psychoanalytic therapy? Who is the analyst? Who is the patient? If psychoanalysis is a process of transformation, what do these practices and our engagement with them encourage us to risk personally, socially, and politically? It is in considering these questions that we are able to move from the intimate life of the consulting room to an intimately complex psychic, social, and political world. Ultimately, the author aims to find a space in which the individual affects (such as anxiety and crying) experienced while fully engaging with an artwork (through transference) can be dissipated or released, as a form of subjective transformation, and ultimately be mobilized as a form of political and collective action.

Keywords: contemporary art, transference, psychoanalysis, anxiety, crying, Louise Bourgeois, Andrea Fraser

Bio: Dr Joanne Morra is Reader in Art History and Theory at Central Saint Martins, University of the Arts London. She runs The Doctoral Platform at CSM, and is Founding Principal Editor of Journal of Visual Culture. She has published widely on modern and contemporary art in New Formations, Art History, Journal of Modern Art, and What is Research in the Visual Arts (eds. Holly \& Smith). Joanne has edited many collections, including The Limits of Death (MUP 2000), The Prosthetic Impulse: From a Posthuman Present to a Biocultural Future (MIT 2006), Visual Culture: Critical Concepts in Media and Cultural Studies, 4 volumes (Routledge 2006), Acts of Translation (with Bal, Sage 2007). Recent activities include the exhibition Saying It (Freud Museum London 2012), Intimacy Unguarded: Autobiography, Biography, Memoir (with Talbot, 2013 -), 50 Years of Art and Objecthood: Traces, Impact, Critique in 
Journal of Visual Culture (with Green, Sage 2017), and Inside the Freud Museums: History, Memory and Site-Responsive Art (I.B. Tauris 2017).

It is not a fact that transference emerges with greater intensity during psychoanalysis than outside it.

Sigmund Freud (2001 [1912]: 101)

His (the analyst's) interpretation should intervene at some point of urgency in the unconscious material and so open up a way to the child's unconscious mind.

Melanie Klein (1960 [1932]: 51)

I can't do it by myself.

Andrea Fraser (2012)

We enter into psychoanalysis when we can no longer go on as we are: we are in need of change; something has to give; a transformation must take place. In having reached such a critical point in our lives, being in analysis is one of the most intimate experiences we can have. In the space of the consulting room we reveal, as best as we can, to our analyst, and most importantly to ourselves: our anxieties, fears, desires, fantasies, and failures; our contradictions and frailties as human beings. In doing so, we attempt to work them through, to articulate and understand them, to discover a way to go on, and live more pleasurably.

Many analysands have granted us access to their experience of being in analysis in the form of a memoir or diary: they range from the patients of Sigmund Freud (Hilda Doolittle [H.D. 1956/1974], and Sergei Pankejeff better known as the Wolf-Man [1989]), to writers and academics (Marie Cardinal [1993], Anaïs Nin [1967/1996], Bonnie Friedman [2002], Georges Perec (1999 [1977]), and Eve Kosofsky Sedgwick [1999]), to analysts themselves who have undergone psychoanalytic treatment as a part of their training to become therapists (Dan Gunn [2002], Nini Herman [1985/2001], and Marion Milner [1934/1986]). Artists have also put to use in their creative practice the personal and autobiographical material generated from their psychoanalysis (for instance Lygia Clark, Grayson Perry, Barbara Visser, Bettina von Zwehl as well as Louise Bourgeois and Andrea Fraser both of whom I focus on in this article). Of significance in all of these autobiographical works (whether memoir, diary, or artwork) is the way in which these individuals have revealed and shared something of their personal experience - have unguarded the intimacies - of what took place inside the consulting room, thereby disclosing to us aspects of themselves as elicited by this very particular mode of dialogic self-reflection: psychoanalysis. By putting this most personal and intimate of work into the public realm, whether in a book, diary or on display in a gallery, these writers and artists risk a great deal. What is the risk? Why take it? And for whom? 
For quite some time now I have been interested in the possibilities offered to us in analyzing the relationships between the affective psychic processes that take place within the consulting room, and those that occur within the artist's studio, writer's study, and art gallery. Without reducing the singularity (and thus differences) of each of these practices and the spaces in which they take place, I have wondered about the psychoanalytic correlation between them and what each can give the others. Is it possible to think of them as singular yet analogous practices and spaces? In engaging with this conception, I have found myself asking: what is to be learned from thinking about the practice of making a work of art, writing a text or curating an exhibition in relation to how a psychoanalytic treatment begins? The resistant psychic processes of remembering, repeating and working through? The affective and interpretative psychoanalytic practices of transference, transference-love, and actingout? The failure of an anaysis? And the interminabile ending associated with a psychoanalytic treatment? (Morra, 2008; 2012; 2017a; 2017b)

Continuing this interest in the potential alliance between psychoanalytic and artistic practice through the project Initmacy Unguarded, and more specifically in this article, I have taken this opportunity to consider the work of artists who have provided us with their experience of being in analysis, and the questions raised by these artworks and practices. In doing this, what has struck me most forcefully are the ways in which some of these works represent the process of psychoanalysis, while others enact it.

By this I mean that in representing the experience of being in analysis, some artists have depicted and described this experience in such a way as to emotively and aesthetically convey the important knowledge and work accomplished within the clinical setting. Other artists who enact their experience of being in analysis use artworks or writing in order to perform what takes place in a consulting room (the process, the mechanisms, the labour, and also the fruits of that labour) as a means of affectively engaging the viewer or reader. As a result of this enactment, the viewer is encouraged to experience something of the process of being in analysis with them or being in analysis as such. In bringing the viewer into the realm of the psychoanalytic consulting room as a dialogic and transformative space, these artists are attempting to put the psychoanalytic practices that I mentioned earlier - for example, working through, transference, and acting out - into action. The result of this is a fantasmatic transformation of the space of the gallery into the consulting room: an invitation to the viewer to enter and engage with this psychoanalytic space and the practices that take place within it, outside of the consulting room.

In this article, I focus on this enactment. I examine how the enactment of the experience of being in analysis is key to these artistic practices. More precisely, I suggest that enactment is a result of us having a specifically psychoanalytic, intrapsychic (within the subject) and intersubjective (between subjects) experience that is analogous to the process of transference. Through the framework of transference, I consider how we become fully engaged with the artist-as-patient in the work - and ourself-as-patient - and how this engagement solicits something of ourselves: requires something from us; opens up our 
affective emotional and psychic investments in the work; and asks us to consider what the experience means to us personally, politically, and socially. My aim is to find a space in which the individual's affective experience while fully engaging with an artwork, through transference, can be held on to in its affective capacity, or dissipated and released as forms of intrapsychic transformation, and ultimately mobilized as a form of inter-subjective political and collective action. ${ }^{1}$

\section{What is transference?}

For Freud, the process of transference is crucial to psychoanalysis (2001 [1905/1901]; 2001 [1912]; 2001 [1914b]; 2001 [1915-1917]; 2001 [1937]). In 1901, he noted that transferences are 'new editions or facsimiles of the impulses and phantasies which are aroused during the progress of the analysis [... and that they] replace some earlier person by the person of the physician' (2001 [1905/1901]: 116). In other words, the old object and relationships of our unconscious fantasies and wishes are made new when they are transferred onto our relationship with our analyst. Freud's idea of transference is extended and transformed a generation later by psychoanalyst Melanie Klein for whom transference includes unconscious object relations that are associated with real life events and fantasy from our past, but crucially also ones in the present - thus her interest in what she and others called the 'here and now' of the clinical setting. For Klein, transferences experienced within the consulting room are thus imbued with a complex temporal and spatial dimension in which the past and present, real and fantasy life meet (1960 [1932]; 1975). In the clinical setting, transferences that are directed towards the analyst can be positive (affectionate) or negative (hostile). For psychoanalysis, the patient's 'cure' is dependent upon the analyst recognizing, interpreting and communicating the transferences while working with the patient so as to dissipate and thus overcome them.

Transference is not though confined to the consulting room. As early as 1912, as noted in the epigraph to this article, Freud understood that '[i]t is not a fact that transference emerges with greater intensity during psychoanalysis than outside it', thus opening up the way for analysts to theorize how other affective experiences outside of the clinical setting are also forms of psychic transference (1912). One of these thinkers is the contemporary

\footnotetext{
${ }^{1}$ The notion of 'enactment' that I am using builds upon while also diverging from Andrea Fraser's work. Fraser employs the concept of enactment in order to rethink the idea of performativity (J.L. Austin and Judith Butler). She takes her cue from the work of relational psychoanalysis and its understanding of transference as a means of ensuring that artistic practice (and pedagogy) involves both an intrapsychic and intersubjective framework that opens up onto social and political realms. Fraser's most recent articulation of this can be found in 2015, 2016a, 2016b. What I am highlighting in this article is the 'affective' quality of enactment. Thus, my focus on anxiety and crying. My aim is to find a space in which the individual 'affects' experienced while fully engaging with an artwork (through transference) can be understood as individual feelings, as well as instigate the mobilization of political and collective action.
} 
psychoanalyst Jean Laplanche. For him, cultural production itself has the potential to be a site of transference. Laplanche suggests that spaces and practices of cultural production are sites in which psychic elaboration and working through can take place as a means of better understanding the other within ourselves (the unconscious) and an other (person) we encounter. As a result, transference which has both an intrapsychic and intersubjective structure, is tied to a broader social, political and ethical world. (Laplanche, 1989 [1987]; 1999). Following Freud and especially Laplanche, it is possible for me to assert that transference also occurs in cultural sites of production such as the artist's studio, the writer's study, and the gallery; and thus is a process that contributes to the production and reception of artworks, pieces of writing, and exhibitions.

Of interest to me in this article is this expanded understanding of transference - a fantasy and reality experienced in the 'here and now' of the consulting room, and, in these sites of cultural production, together with the things that are constituted therein, artworks for instance - and the very real and often disruptive emotional and psychological affects that are a part of this experience for the viewer. In encountering and interpreting artworks and writings in these cultural spaces that enact, rather than represent the patient's experience of being in analysis, specifically the experience of transference, I would like to ask: What do we experience? How might we respond and engage with such intimate work? What is being required of us as viewers? Are we being invited to participate in a form of psychoanalytic therapy? Who is the analyst? Who is the patient? If psychoanalysis is a process of transformation, what do these practices and our engagement with them encourage us to risk personally, socially, and politically? It is in considering these questions that we are able to move from the intimate life of the consulting room to an intimately complex psychic, social, and political world.

\section{Breathless}

In 1958, six years into her psychoanalysis with the Freudian Dr Henry Lowenfeld, Louise Bourgeois wrote the following note in pencil on a blank sheet of white typing paper:

The analysis is a jip

is a trap

is a job

is a privilege

is a luxury

is a duty

is a duty towards myself

my husband my parents

my children my 
is a shame

is a farce

is a love affaire

is a rendez-vous

is a cat + mouse game

is a boat to drive

is an internment

is a joke

makes me powerless

makes me into a cop

is a bad dream

is my interest

is my field of study -

is more than I can manage

makes me furious

is a bore

is a nuisance

is a pain in the neck -

I first read this incisive reflection on the experience of being in psychoanalysis during my initial visit to the Bourgeois exhibition The Return of the Repressed curated by Philip LarrattSmith at the Freud Museum London in Spring 2012. This nuanced piece of intimate selfreflection was one of over 1,000 pieces of what are called the artist's 'psychoanalytic writing' - notes, thoughts, lists, sometimes accompanied by doodles or drawings written on ubiquitous sheets of typing or graph paper, index cards, writing pads, or stationary - that were discovered in batches, first in 2004 and then in 2010, by Bourgeois' assistant Jerry Gorovoy in the artist's Chelsea home in New York City. These texts, not formal artworks by any means, were personal pieces of writing related to the more than 30 years of psychoanalytic treatment that Bourgeois undertook between 1951 and 1985. This was a dramatic discovery given Bourgeois' long-standing public criticism of psychoanalysis as a theory and therapeutic practice. A selection of these writings - framed and curated (thereby blurring the boundary of their status as pieces of writing or artworks) - were exhibited along with a group of Bourgeois' sculptures in the Freud Museum London, a deeply appropriate setting for these all of these works given the site's fundamental connection to the mise-enscène of the consulting room (Freud's famous couch and all of his belongings reside at 20 Maresfield Gardens), as well as the Museum's vital relationship to the history and memory of psychoanalysis. 


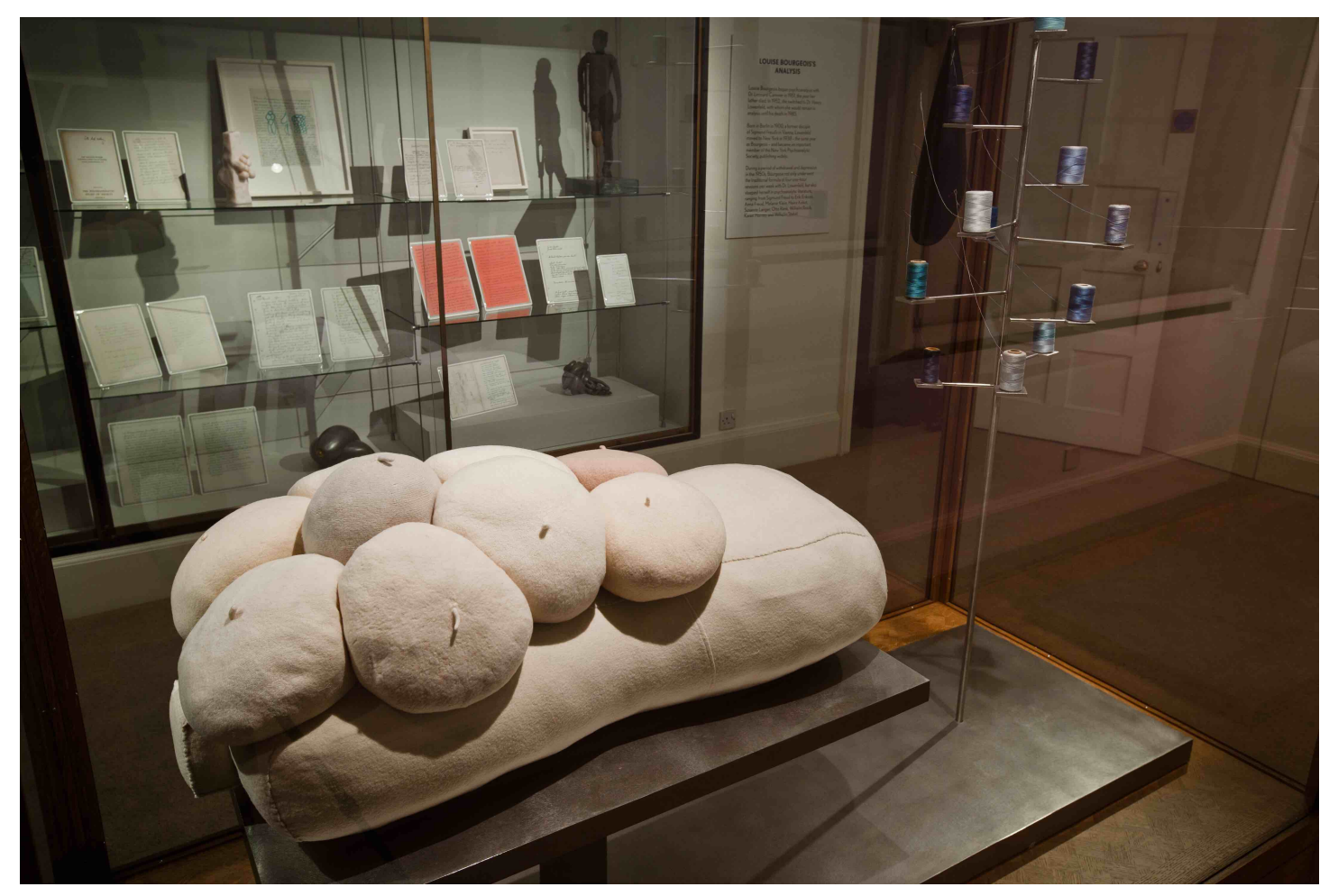

Louise Bourgeois, Untitled (2010), with small works and writings in the vitrines

Louise Bourgeois: The Return of the Repressed at the Freud Museum in London, 2012

Photo: Ollie Harrop, ( The Easton Foundation/Licensed by DACS, UK 2017

Close by to Bourgeois' perceptive and witty précis of being in psychoanalysis, I also encountered in the exhibition a short text in pencil on blank, white typing paper from c. 1957 disclosing the artist's multiple senses of failure:

step No 4 -

I have failed as a wife

as a woman

as a mother

as a hostess

as an artist

as a business woman

and as any 47 -

as a friend

as a daughter

as a sister

I have not failed as a

truth seeker

lowest ebb 


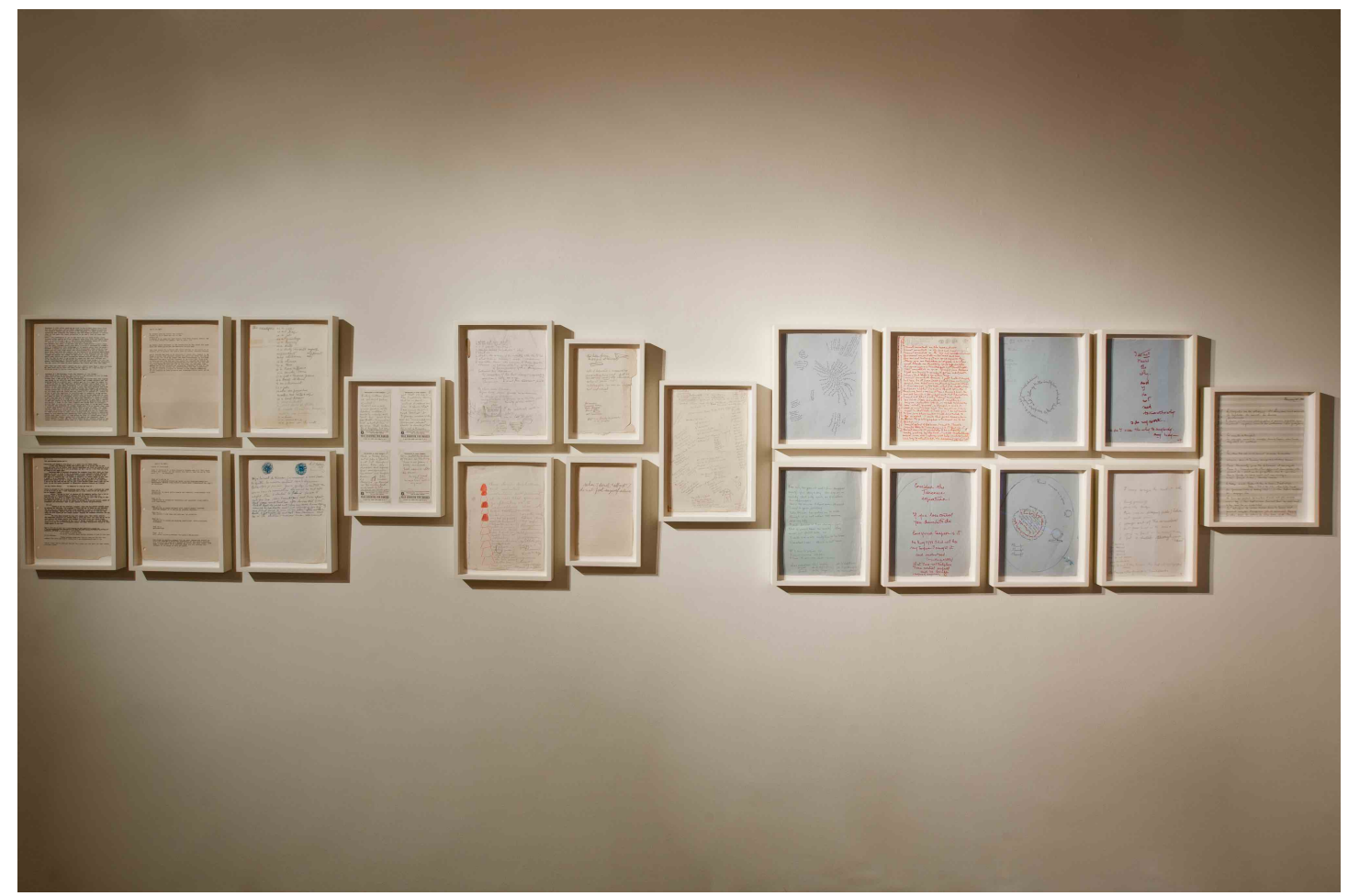

Framed archival documents by Louise Bourgeois from the Louise Bourgeois Archive Louise Bourgeois: The Return of the Repressed at the Freud Museum in London in 2012. Photo: Ollie Harrop, (C) The Easton Foundation/Licensed by DACS, UK 2017

Surrounding me, I saw evidence of the complexity with which women engage in the world through a vast array of roles and the many senses of failure this can produce. Bourgeois' sculptures manifested this potential failure in the fragmented bodies with missing or broken limbs; torsos with multiple breasts; genitals excised from figures; and knives bearing down on partial bodies. The intense affectivity of these writings surrounded by her artworks pressed down upon me too as I moved on to another piece of her psychoanalytic writings. Here, I found that the artist as truth seeker, even at her lowest ebb, was driven to continue the grueling activity of probing her psyche. This time, in the form of a list from c. 1962 written in red ink with black and blue ink additions on typing paper. Bourgeois was wrestling with the demands of her personal desires and their suppression by a multitude of social and political prohibitions:

\footnotetext{
I want to get

I want to keep

I want to say.

I want to tell

I want to see

I want to learn

I want to know

I want to know
} 

I want to control
I want to hold
I want to feel
I want to remember
I want to go
I want to want
I want to find
I want to finish
I want to get rid of
I want to clean
I want to be good
I want to be better
I want to do it
I want to show
I want to outdo
I want to top it
I want to accom$$
\text { plish mastery }
$$
I want the means to get
I want the tools
I want mastery
I want omnipotence
I want to manipulate

The list continued to detail many more desires,

I want to be noticed

I want to be given

I want to be loved

I want to be right

I want to prove

I want to survive

to avoid death

destruction

I want to be free

$$
\text { guilt }
$$

I want to please

I want to avoid

I want to escape

I have to escape 
And then suddenly things took a dramatic turn. I read:

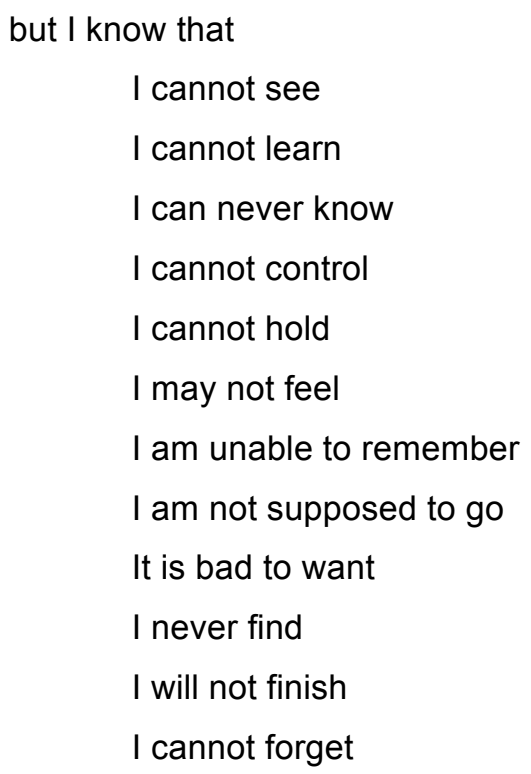

And later still:

You accomplish nothing

Then, of course, you despair

and you have reasons to. The voice of reason and of experience the real

would always

say no

Overwhelmed by these desires, failures and prohibitions, and importantly, recognizing them within myself, I found I was unable to continue reading this particular list. I turned away.

Relieved of having to engage with this list, I was drawn to a small piece of personal stationary from the artist's $18^{\text {th }}$ street apartment in New York City. While living here, at the beginning of her analysis in 1951, Bourgeois made several doodles as well as noting in black ink and pencil on the stationary that:

The drawing is the most

basic psychologique [sic] release

the modern artist is

caught in a delemna [sic] in that

he considers art as a psychological

release and

at the same

time wants to 
have an

audience

I was this audience. I knew it. I felt it. I began to experience claustrophobia. I quickly turned to another of Bourgeois' statements from c.1965, written with pencil on ruled paper, where the artist noted:

When I do not 'attack I /do not feel myself alive.

Both beguiled and ensnared by these pieces of writing, I moved back to Bourgeois' list of desires and prohibitions. Guided by the artist, I felt a comparable despair, maybe it was her despair: I was with her, identifying very decisively with her emotional turmoil, which, given my tension and claustrophobic response, we now shared.

As I continued to read, I arrived at the last few lines of the 5-page list of wants and desires: Bourgeois had found a form of equilibrium. Paraphrasing Diogenes and Anatole France, she wrote:

To be rich is to want less than

one's means -

By that point though, it was too late for me. Too many experiences, memories, and emotions had been evoked and were alive within me. Bourgeois' uncompromising selfreflections demanding of my attention, surrounded by her artworks and the objects within 20 Maresfield Gardens had come together to trap me: the affective intensity of this experience left no room for psychological and emotional release. I realized that my encounter was overdetermined, it was full of contradictions and irreducible affect: I was full of sympathy and even empathy for Bourgeois; but this quickly turned to irritation, astonishment and disbelief; followed by laughter and delight; only for that to turn to hostility and anger - towards Bourgeois, towards myself, towards the social and political structures that construct and foster these deeply conflictual emotional and psychic experiences of femininity. Deeply affected by this encounter, I became extremely anxious: I began to tremble: I could no longer breathe. I had to leave: I quickly walked out of the Museum's front door and attempted to still my emotions and catch my breath.

The highly charged emotional and psychic affect of this experience is worth considering. What am I to make of the complexity and intensity of feelings it evoked: the empathetic engagement and discord of empathy and panic that I experienced? The bodily affect in the form of anxiety, trembling, and breathlessness that compelled me to walk out? Given the 
ubiquity of these affects within the mise-en-scene of Freud's consulting room, Anna Freud's consulting room, all psychoanalytic consulting rooms for that matter, just there, in 20 Maresfield Gardens, did I experience some form of psychoanalytic transference? If so, what took place? Why? And what does it tell us about the potential of personal writing, art practice, experience and transference? I'll return to this experience shortly, but first, let me take a look at another instance of transference as artistic affect.

\section{Point of Urgency}

Andrea Fraser has had a long-term interest in psychoanalysis. Brought to psychoanalysis by feminism, the artist has said she has found in psychoanalysis a theory of the unconscious; an understanding of the formation and function of the human subject and sexuality; and a means of productively dealing with the subjective and intersubjective relationships that constitute the personal, political and social structures within which we live. At the same time, Fraser has been attuned to the transformative potential of psychoanalysis as a clinical practice. This dual enlisting of psychoanalysis - as a theory and practice - has led Fraser to consider the ways in which psychoanalysis is meant to 'cure' individuals; how this psychic change transforms the subject and their relationships to others; and how if artists are, as she states, 'agents of change', perhaps psychoanalysis can offer artists a model for enabling such change (Fraser 2016c: 2).

In endeavoring to embody transformative change within her art practice, Fraser explains in a recent interview with Thyrza Nichols Goodeve for the art and culture journal The Brooklyn Rail that she uses herself as 'an instrument of research'. This process enables the artist to

use [...] my own affective responses to things to locate the point of urgency in a situation [so that...] I can work on and from that point.

[...]

The principle of interpreting at 'the point of urgency' comes from James Strachey's essay about the therapeutic action of psychoanalysis, which is an important reference for me. He [...] got it from Melanie Klein [...]. The idea is that an interpretation can only be mutative, that is transformative, when made at a point of urgency. (2016c: 3 )

For Klein, as I quoted in one of this article's epigraphs, the analyst's 'interpretation should intervene at some point of urgency in the unconscious material and so open up a way to the child's unconscious mind'. The point of urgency is thus an opportunity: it is the moment in which an analyst should intervene in the analytic situation and make an interpretation so as to 
effect positive change in the patient. In order to recognize a point of urgency, the analyst must be attuned to repetitive moments of negative transference during which the patient projects negative unconscious feelings onto the analyst. For Klein, these negative feelings are displayed through repetitive, negative actions and by 'an intensity of feeling' that is associated with them. Klein explains that this intensity of feeling is the 'affect belonging to the content' of the actions and the unconscious and conscious memories and experiences these actions raise. Often, an intensity of feeling occurs in the form of 'anxiety'. At such a point of urgency, it is only the work of interpretation that can 'cut short' or 'scale down' the anxiety and initiate the transformative process of psychoanalysis (Klein 1960 [1932]: 51-2). This transformative process is what Strachey calls the 'mutative' aspect of psychoanalysis (1999 [1934]).

As a model for artistic practice, Fraser is invested in the mutative potential of psychoanalysis at the point of urgency, but, also recognizes that this is an extremely difficult and demanding task because, as the artist tells Goodeve:

The [point of urgency] is a point of tremendous anxiety! [Laughter.] Which is why it can be so difficult to locate the point of urgency - it's obscured by all sorts of defenses against that anxiety. And which is part of the problem I have as an artist: a project doesn't feel worthwhile unless it makes me extremely anxious! And then I just want to retire. (2016c: 3)

Fraser does not retire. Perhaps each opportunity (or even every potential opportunity) offered by a point of urgency, with its associated intensity of feeling, and potential for transformation, is worth taking another risk?

Fraser's installation Projection (2008) is just such an occasion, such a risk: an artwork that risks unguarding some of the most intimate aspects of herself through the disclosure of her time within psychotherapy. Having undergone a highly confrontational form of psychotherapy known as Intensive Short-Term Dynamic Psychotherapy (ISTDP), Fraser developed the artwork Projection. Although based on psychoanalysis, ISTDP is a relatively recent form of therapy that attempts to accelerate the process of psychoanalytic treatment by employing a series of psychodynamic principles in an intense and aggressive form. The key ideas of ISTDP are as follows: that through a hard-hitting process the therapeutic effects of the treatment can appear within the first few sessions; that certain complicated developments within traditional therapy, such as transference dependence, acting out, and difficulties over termination can be eliminated; and that by the end of the treatment, all traces of the patient's original disturbances are dissipated (Neborsky 2001).

Projection re-works the 15 hours of transcripts based on video recordings of Fraser's ISTDP treatment (videotaping the sessions is part of this form of psychotherapy). In a twochannel video work, a life-size Fraser, seated on an orange Arne Jacobsen Egg Chair wearing a simple black tank top, forest green leggings and black flat shoes plays the roles of both the analyst and patient. Set up on opposite sides of a long, blacked-out room, the patient 
and analyst face one another; as one figure emerges and speaks, the other fades away: enacting an exchange between them.
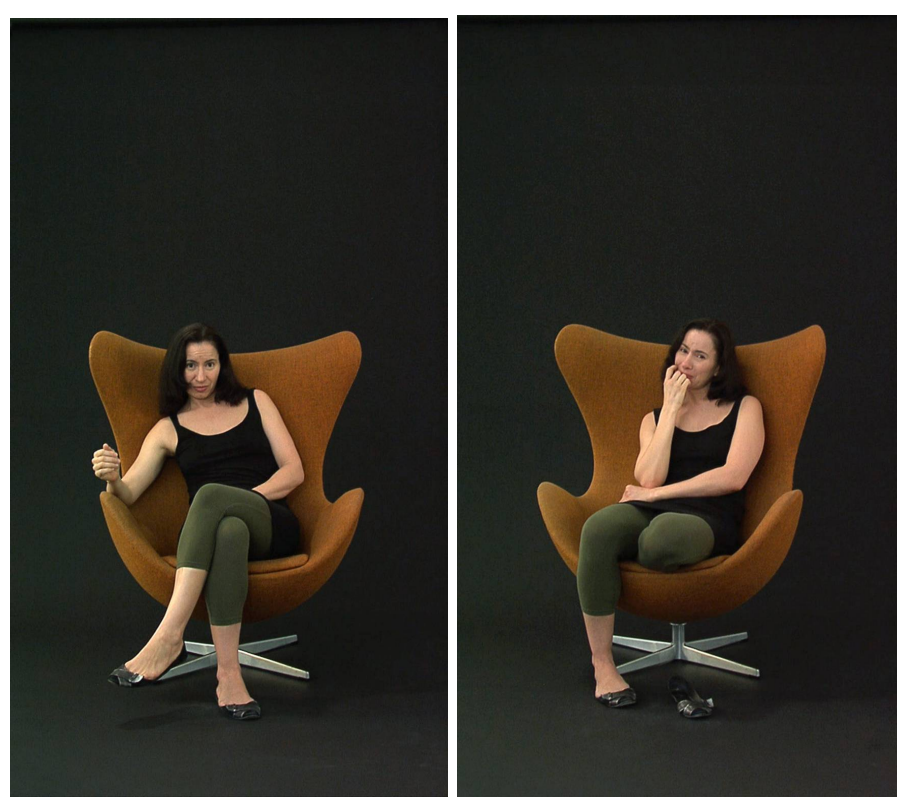

Andrea Fraser, Projection, 2008, Galerie Nagel Draxler, Berlin.

A severe and often disturbing dialogue takes place between the analyst and patient in Projection. The unremitting conversation opens up the complex emotional, psychological, and intellectual world of an artist who practices institutional critique, through a set of challenging and often intimidating provocations, injunctions and interpretations made by the analyst. The discussion ranges from the history of aesthetics, the problematic of institutional critique, the competitive and envious nature of the art world and its financial inequities, to love, power, guilt, sadness, loss, trauma, responsibility, humor, desire, fantasy, and pleasure.

Sometimes with kindness, but most often through aggressive techniques, the analyst locates moments of transference and uses them to force the patient to react: the analyst asks probing questions, attacks her patient's responses, frustrates the patient, interrogates what the patient may be feeling, provokes a heightened response, and bluntly interprets her patient's transferences. The patient attempts to stand her ground and sometimes responds with clarifications, irony, and quiet self-reflection, although most often the patient demonstrates frustration, anger, aggression, anxiety, and fear during the process, and she cries regularly; the patient sheds many tears. At one point the analyst cuttingly questions her patient's tears by insinuating inauthenticity:

Left Screen: Right now, though, I mean, are these tears genuine, or...?

$[\ldots]$

The worst thing you can do here is perform to what you think I want from you. (Projection, 2008) 
In the artwork Projection, Fraser has sharpened the intensity of ISTDP, and the affective enactment of the installation as a site of transference through several points of artistic mediation. The artist has edited the transcript of her treatment into short monologues (condensing the impact of an already forceful therapy); she has substituted all specific nouns and proper names with shifting indexical and demonstrative terms (no individual person or place is ever named); she has also substituted the present for the past tense (everything takes place in the 'here and now'), and has substituted second for third person pronouns (all references to 'him' or 'her' are now to a 'you'). As a result of these alterations, Fraser has ensured that the performative aspect of the language employed engages the spectator directly. We are not distracted by any distinguishing specificities, rather we are constantly being signaled through direct address: 'l' and 'you' are the only personal pronouns used, and as the exchange only occurs within the present tense, the viewer is contained in the 'here and now' of the experience.

From our position in between both analyst and patient, we are the addressee, the object of the discourse, and the screen onto which the various projections and transferences take place. As we turn from one side to another, physically shifting our body, we enter the psychoanalytic frame of the patient and then analyst, we are constituted by the enactment of the clinical setting in the installation: we move back and forth between them, listening to the dialogue, and affected by the emotions and psychic realties of which we are a part. We become locked into this dialogic and affective space: we are made to be present during a highly emotive therapeutic situation in which there is little respite.

This experience is heightened by the fact that Fraser is playing both the roles of the analyst and patient, complicating even further the positions of 'l' and 'you' between these two figures, and their relationship to us. At times we are hailed by the patient, at times by the analyst, but always by the figure of the artist. As has been noted about Projection by art critic Sven Lütticken: 'Far from being an advertisement for ISTDP, of which Fraser is very critical, Projection exploits the charged situation by playing both parties - though on opposing projections - this gives the sensation of a subjectivity in dissolution, of a super-ego attacking a crumbling and struggling self' (2015: 36). The 'sensation' that Lütticken identifies, 'of a subjectivity in dissolution', is the sensation that we experience while engaging with Projection. This disturbing affect is brought to bear on the viewer by the way in which Projection enacts for us the problematic nature of ISTDP: this is not a practice of mutative transformation (the kind that Fraser cherishes), but a form of encouraging the subject's aggressive dissolution.

The practice of ISTDP is quite the opposite of Strachey's understanding of the mutative function of psychoanalysis that Fraser finds crucial to her practice. For Strachey, a mutative transformation involves the interpretation of the patient's transference at a point of urgency (following Klein), based on a positive reconstruction of the patient's super-ego. This takes place through a slow, careful and methodical interpretative process that relieves the patient of her aggressive super-ego and replaces it with a diminished one. Such a 
transformation enables the strengthening of the ego, and precipitates the dissipation of symptoms, leading to a 'cure'. Vitally, to reach this point much work must to be done to diminish the intensity of feelings associated with a point of urgency - the anxiety, the crying and much time is required for this process to take hold (Strachey 1999 [1934]).

On 28 November 2013, while Projection was on display at Tate Modern, Fraser gave a public lecture on her work. At the end of a highly engaging talk, the then Director of Tate Modern, Chris Dercon joined Fraser for a Q\&A session. At one point, Dercon pressed Fraser on the political impetus behind her work, and asked if she would expand upon the 'critique' of institutional critique that she has written about: the overdetermined political conditions this raises for artistic practice, and what needs to be done (Fraser 2007; 2011; 2012a). Asking Fraser to discuss potential solutions, the artist explained that there are no solutions.

In fact, for Fraser, artists, art historians, critics and curators are a part of the problem, and if at any moment they believe themselves to be part of the solution, they/we have lost the battle. The practice of critique is endless: it must go on, even when we cannot bear for it to continue. In an emotional conclusion, Fraser rallied:

And I want to be challenged that way, and I will be found faulty, but that's ok. [...] But, I can't do it by myself [...] I want the field to do it, and I want the field to demand that of me, and I want the field to demand it of other artists too. So we are in it together. (2012b)

And then she began to cry.

\section{From An Individual Feeling to Collective Action}

Returning to my affective response to the intimacy of Bourgeois' psychoanalytic writing, I can now ask: was my intensity of feeling, my anxiety, a point of urgency? Was what led me to need to walk out of the exhibition a moment of transference?

Bourgeois' psychoanalytic writings demonstrate both the importance of psychoanalysis in her life and in her artistic practice (something she denied throughout her lifetime, although she did agree to have the pieces of writing exhibited before she died). These documents also form an extraordinary intimate 'case history' of the artist: an intimate self-reflection of her psychic and emotional life. Taken as a case history, they offer an insight into the complex negotiations of femininity that are at stake in being an artist, and the dynamic affective potential of the emotional and psychic work that takes place in the intimate 
space of the consulting room. In these psychoanalytic writings, as art historian Mignon Nixon puts it:

Bourgeois holds herself to account daily, even hourly, in a painstaking catalogue of self-examination, duly acknowledging the pleasures of her own beastliness $[\ldots]$ and the pain of its boomerang effects [...] Unsparing but never self-lacerating, [... Bourgeois] recounts the 'psychic facts' of life, [...] the destructive impulses in one's life. (2012: 87)

Nixon continues her interpretation of Bourgeois' writings stating that what we are witnessing is a form of 'negative transference' (87). For Nixon, the traces within Bourgeois' writing uncover a politically and ethically charged Kleinian subject for whom aggression and violence are followed by anxiety, guilt, fear, and then the need for reparation. These feelings are key for Klein; they are the primary focus of a Kleinian psychoanalysis and its understanding of negative transference.

A further reading of Bourgeois' psychoanalytic writings is offered by psychoanalyst Juliet Mitchell that establishes a very precise interpretation of the artist's negative transference as a form of 'acting out'. Acting out occurs when repressed memories are not remembered, and worked through, but repeated through negative actions directed at the analyst. In the clinical setting, acting out is a form of resistance that does not lead to a 'cure' (Freud, 2001 [1914a]). Mitchell argues in her analysis of Bourgeois' writings that the artist was able to 'use' her symptoms, in a psychoanalytic sense, to continue to make her artwork. The psychoanalyst notices that Bourgeois' writings are filled with 'an imbrication of various and multiple preoccupations such as would arise within a clinical session' (2012: 47). By focusing on Bourgeois' jealousy, Mitchell concludes that, if psychoanalysis is a process through which the patient is relieved of their symptoms 'there seems little to suggest that Bourgeois was relieved of many (or any) of the symptoms that beset her [...]. She needed them all' (47-8). Mitchell proposes that Bourgeois' wish to become cured was subordinated to her drive for artistic production. The psychoanalyst explains how in acting out, rather than working through, Bourgeois was able to

keep the emotions raw and alive because her sculpture was to make conscious what we all experience unconsciously. She thus has to have more not fewer of her symptoms; both bad and good experiences must be intensified. [...] she goes into what is unbearable/unknowable (which is why it is repressed) and makes it conscious in visual form. (50-1) 
For Mitchell, Bourgeois' acting out allowed the artist to go into that which was 'unbearable/unknowable' and present this in visual and textual form. In order to continue working as an artist, Mitchell argues that acting out took place for Bourgeois in lieu of a cure.

In following Nixon and Mitchell's analyses of Bourgeois psychoanalytic writing and artwork, I wonder if the confrontations that I experienced (echoing back to Bourgeois' claim that 'When I do not "attack" I/ do not feel myself alive'), combined with the artist's understanding that the psychological release associated with artistic practice requires an audience, were an affect of this negative transference? Was my emotional reaction to the show a mirroring of Bourgeois' acting out, a love-hate response to an intense encounter with a forceful Kleinian subject? Was my walking out of the exhibition a form of 'acting out', a reaction to being subsumed into this Kleinian world? And what about the anxiety: what am I to make of that?

Freud had much to say about anxiety throughout his career (2001 (1905/1901]; [1915-17]; [1926/1925]; [1932/1933]). Although his ideas on it changed as he accumulated a greater understanding of anxiety, one point remained constant:

Anxiety has an unmistakable relation to expectation: it is anxiety about something. It has a quality of indefiniteness and lack of object. In precise speech we use the word 'fear' rather than 'anxiety' if it has found an object. [...] Anxiety is an 'affective reaction' to something. [...] for analysis shows that to the known real danger an unknown instinctual one is attached. (2001 [1926/1925]: 166)

Anxiety is, in other words, an affect, a 'signal' denoting an impending danger that reawakens a repressed memory of an earlier danger (Freud 2001 [1932/1933: 81). The feeling associated with the original situation - anxiety - emerges, but the memory does not. Although internal dangers change throughout one's life, for Freud they always involve a loss or separation from a loved object or a loss of love. Thus, although anxiety is without a definite object (the state of anxiety is not roused by a particular object like in fear), anxiety as an affect signals the potential threat of an occurrence. Because of this lack of a discernable and definable object, anxiety has a quality of 'indefiniteness'.

We have encountered anxiety before: in Klein's analysis of a point of urgency within transference. We will remember that during transference, a point of urgency can be recognized by the patient's repeated actions, and the intensity of feeling associated with them: anxiety. Was my experience of encountering Bourgeois' psychoanalytic writings inside the Freud Museum a point of urgency? If so, who are the subjects enacting this transference? And what is the object or love that is lost?

The affective emotional and psychic reaction that I experienced in the Bourgeois exhibition was deeply connected to the artist's lists of wants, prohibitions and failures, linked to the multiple roles expected of femininity within our culture; an experience that was so 
strongly embodied in the personal and political that it left me trembling and breathless, so anxious that I had to walk out of the show. In this instance of being with Bourgeois in psychoanalysis, there seem to be two separate but related moments where an intimacy is revealed, shared and unguarded. They occur as enactments of the psychoanalytic process known as 'ambivalence' - a type of psychoanalytic transference where love and hate are directed at the same object or are acted out with different objects. One of these moments takes place within Bourgeois: between her self and her analyst as embodied in her psychoanalytic writings: and these provide the foundation for her artwork (as Nixon and Mitchell have suggested). The other moment of ambivalence takes place intersubjectively between myself and Bourgeois' writing, and their relationship to her artworks and the space of the Freud Museum, an experience that was embodied intrapsychically to such a powerful extent that I had to leave the site.

But, what about the series of conflicting and multiple emotions that I felt - not just love and hate, but also, sympathy, empathy, anger, frustration, delight, surprise, and disappointment - emotions that in their overdetermination came together in my affective anxious state?

In the formulation I am carrying out in this article, an artistic encounter that produces an affective reaction such as anxiety is a breach, a point of urgency that breaks into and upsets the functioning of the self, it is an encounter that offers us the potential for a transformative moment: through interpretation, this encounter becomes a space in which to learn something about ourselves and what art can do.

What I would like to propose from reflecting upon this personal point of urgency is that anxiety is not singular or ambivalent, as Freud and Klein would have it, but multiple. It is clear to me that I experienced multiple and conflicting emotions that led to anxiety. If, as psychoanalysis has taught us, anxiety is an amorphous feeling that grows as new situations trigger the initial repressed one, cover it over, and become associated with it, anxiety is the affect of multiple conscious and unconscious situations and their associated emotions. We might wish to think about anxiety as an affective response that is like a bunch of burrs that catch hold of one another, cling to each other, and accumulate over time but produce an instant affect. What this experience with Bourgeois' writing has taught me is that anxiety seems to function as a contingent chain of emotions that overwhelm the individual because they occur at a singular point in time: a point of urgency. The contradictory feelings and temporalities associated with the emergence of an initial emotional response comes to join subsequent impending encounters, and the feelings associated with them, and all of these situations and emotions get conflated into a singularity without synthesis, without resolution: anxiety is the chaos of these feelings and experiences, into a point of urgency. Anxiety is more than an ambivalence (something that brings together love and hate); it is a form of what I would call affective diffraction, a this and this and this and this, etc. Bourgeois' lists are an articulation of this affective diffraction: they are wishes, failures and impossibilities whose affect accrues as I move through and across each piece of writing, building anxiety in me 
rather than cutting it down into simple, singular, interpretable and manageable parts. The experience of engaging with this psychoanalytic writing was one of transference where my anxiety confirms an experiencing of a point of urgency. My interpretation of anxiety as a form of affective diffraction constitutes the transformative potential of my own anxiety: it has given me an understanding of the rawness of this experience, and enabled me to mobilize it intrapsychically. I have come to understand something about Bourgeois, about myself, and about anxiety itself: that anxiety is not singular in its manifestation, but multiple, and that this multiplicity works to keep emotions alive and raw (as does Bourgeois' delving into the unknowable/unbearable world of her unconscious as a motor for her artistic practice). The question that remains to be asked of this individual experience is: is it possible for me to mobilize this anxiety and use it for collective action?

What about Fraser's tears?

The patient cries often throughout Projection, which is expected; crying is part and parcel of the work one does in analysis. And what of the tears shed during her conversation with Dercon at Tate Modern? Are these two points of urgency?

Fraser has courageously written about the fact that she has found herself crying in public for many years. In 2004, she had the opportunity of appraising why this might be. The result is the talk entitled 'Why Does Fred Sandback's Work Make Me Cry?' The particular episode of crying that Fraser considers in this talk took place in May 2003 when she first visited Dia: Beacon. Walking around the enormous gallery space at Dia, and spending time with some of 'the art I love most' - Sol Lewitt, Dan Flavin, Donald Judd, On Kawara, Agnes Martin, Blinky Palermo, Robert Ryman - Fraser encountered Sandback's work, and she began to cry. 'I sat down on a bench there, and I wept' (2006: 32). This experience brought to mind a trip to MOMA in the late 1990s where she wept in front of Barnett Newman's Vir Heroicus Sublimis (1950-51), and then again when seeing Ad Reinhardt's work on an adjacent wall. She asks of these experiences: 'What could it be about this extremely reduced kind of art, art so devoid of anything that would normally be considered expressive and affective, that caused me to weep?' (34).

Fraser provides a brilliant analysis of weeping. By combining Freud's work on melancholia, various psychoanalytic readings of tears, and Pierre Bourdieu's understanding of the social constitution of aesthetic experience and its objects, she proposes that:

Just as art cannot exist outside of the field of art, I cannot exist outside of the field of art, at least not as what I am, which is an artist. And this is also the limit of institutional critique. I can attack those internal objects. I can rip at the walls of my institutional body. But I can't tear it down completely, and I can't 
leave it, because I would then not only cease to have an effect within the field; I would also cease to exist. (40)

Fraser comes to the realization that, for her, institutional critique has the structure of melancholia. She notes, following Freud, that the melancholic cannot understand that the lost object is gone, and instead she internalizes it (Freud (2001 [1917/1915]). In this way, the subject identifies with the lost object and turns her feelings of anger, aggressivity and criticism towards herself. As a result, 'the loss of the object [becomes] transformed into a loss in the ego, and the conflict between the ego and the loved person [is] transformed into a cleavage between the criticizing faculty of the ego and the ego as altered by the identification' (Freud in Fraser: 36). This makes melancholia a form of neurosis for Freud because the person is fixed in misunderstanding, and the affect of loss is turned against oneself: melancholia 'show[s] us the ego divided, fallen apart into two pieces, one of which rages against the second' (Freud in Fraser: 36).

Fraser sees this critical, aggressive division within the melancholic as the psychic state of the institutional critic who attacks and critiques the art and practice that constitute herself, and what she does. As a result, Fraser notes that '[f]or me, art is an impossibility', and by extension, 'I myself am impossible. To the extent that I exist, I can only exist as a compromise, a travesty, a fiction, a fraud. The only integrity I can hope to recover is by trying to make sure I'm never misrecognized as anything else' (42). The 'tragedy' for Fraser is thus that this melancholic aggression and ambivalence is experienced in relation to 'what we are' and 'what we love'. At the same time, art offers us 'an attempt at reparation' (43-44).

Within this framework of melancholic ambivalence and violence together with art's reparative potential, Fraser suggests that Sandback's artwork offers her a 'transitional space', as D.W. Winnicott called the 'place that exists between fact and illusion, between reality and fantasy'. This is a space 'where loss can be renegotiated in the re-creation and reparation of things': a space 'that doesn't ask me to feel, and so, I think, allows me to feel, and to be alone, in the presence of this art that's so quiet and still, and makes too little in the way of demands' (45). A 'place of affective possibility', as Fraser eloquently puts it (45).

'Affective possibility'? Perhaps this is the best way to think about Fraser's crying in Projection, in front of Sandback, when talking about her work and what is at stake in art practice during her discussion at Tate Modern, and my anxiety in response to the emotional and psychic work evoked by Bourgeois' psychoanalytic writing. It's like this: when we experience a point of urgency, when an extra-clinical transference bears down on us and we become either so quiet and still that we cry, or so overwhelmed by multiple feelings, emotions and memories 
that we experience anxiety, these are moments of affective possibility; moments in which we stop, reflect and act. $^{2}$

The way in which we approach the affective possibility of these transferential experiences with artworks is not singular: there are many ways to proceed. Bourgeois and Fraser offer us two. On the one hand, there is the desire to keep the contradictions and the unbearable within us, raw and alive as Bourgeois did: to use it as a means of mobilizing an art practice. In this case, the idea of reparation and cure, of working through the contradictions of one's subjectivity, is put to one side and subordinated to the necessity of acting out as the embodiment of an ongoing desire to make art.

I visited the Bourgeois exhibition as part of a book I was working on concerned with contemporary art and the Freud Museums in London and Vienna. I went there in my role as an academic, an art historian and theorist, in psychoanalytic terms, as the 'analyst', the one who is supposed to know. But, my experience taught me something altogether different. It opened up a lack of knowledge, lack of power, lack of desire, the lack of lack (as anxiety itself is for the psychoanalyst Jacques Lacan [2014 \{1962-1963\}]). My affective experience of engaging with Bourgeois psychoanalytic writings was anxiety: an anxiety so overwhelming that I had to walk out of the exhibition. Upon reflection, I came to understand something about Bourgeois' acting out, and my own anxiety: that anxiety is a form of multiplying affect.

Moreover, in the same way as Bourgeois' writing enacted and shared her experience with me, I caught hold of it and can offer my understanding of it to others: perhaps this is a form of multiplying the multiplicity, a means of collective empowerment by sharing and keeping the emotions alive.

On the other hand, there is the work of reparation, the possibility of opening up a transitional space, as Fraser points us to in Winnicott's work, in which our losses can be renegotiated, re-created and repaired (a process Freud called working through). This intrapsychic work establishes the potential of living differently, of engaging with oneself and others in a way that repairs the losses and the damage that ensued from these experiences: to live more pleasurably. This is the possibility offered by Fraser's crying, and her analysis of it; and both constitute forms of self-understanding.

Like the endless process of keeping emotions alive and raw, or the potential for reparation offered by a transitional space, we have arrived at the interminable process of psychoanalysis. Freud recognized at the end of his career, that psychoanalysis is interminable. He was concerned by the fact that even when a patient stops seeing their analyst, the work of psychoanalysis remains unfinished (Freud 2001[1937]). The work carries on. For Laplanche, this is of no concern; in fact it is the potential of psychoanalysis. He notes: 'analysis is $[\ldots]$ interminable. Fortunately for human beings, self-interpretation is, potentially,

\footnotetext{
${ }^{2}$ This brings to mind Lacanian psychoanalyst Dany Nobus understanding of transference in Lacan's work. Nobus writes that for Lacan 'Each time a man speaks to another in an authentic and full manner, there is, in the true sense, transference, symbolic transference something takes place which changes the nature of the two beings present.' And also 'On this symbolic plane, transference operates as the motor of analysis and it can take either the form of love or hate, and quite possibly a mixture of both.' (Nobus 2000: 116 and 109) And I would add, perhaps many more emotions besides love and/or hate.
} 
an infinite process. It will be a very sad day when that process comes to an end!' (Laplanche 1989 [1987]: 164)

In the end, I have arrived at the final epigraph to this article. 'I can't do it by myself', a phrase Fraser used in her conversation with Dercon at Tate Modern in relation to the endless practice of critique. I agree with her. It is true: no one can do it on their own. No one should be asked to do so (which Fraser also makes clear). Perhaps this call made by Fraser is the signal I experienced in my anxious response to Bourgeois' exhibition, perhaps it is a call that is at times required by each of us, a call for collective action.

Is the 'affective possibility' of artworks, that through transference provide us with a form of psychoanalytic enactment, attempting to transform who we are, and what we do intrapsychically and intersubjectively, personally and collectively?

Feminist scholars have been interrogating the emotional and intimate life of women as a form of cultural politics for many years. 'The personal is political' both historicizes and contemporizes that as ongoing. Recently, this has been supplemented by a growing interest in affect as an important catalyst for political analysis and the possibility of collective critique and action. At the same time others have been articulating and negotiating the promises and challenges offered by collective assembly. ${ }^{3}$ Perhaps we can add to this discourse artists who through their artworks are taking a risk and unguarding the intimacies of their psychic lives as well as sharing what is at stake for each of us. Exposing these intimacies, we begin to counter, thereby potentially resist, the alienating atomization of the self, from the state or our communities or ourselves even, and instead, share our experiences as a means of evoking an affective possibility, and provide the grounds for individual and collective action and transformation.

\footnotetext{
${ }^{3}$ This history is vast. For the purposes of my argument and the affective possibility of anxiety, I would like to point to the work of: Butler (2015); Ahmed (2004); Berlant (1998); (2008); (2011); Cvetkovich (2012); Sedgwick (1999); and of course Fraser's work.
} 


\section{References}

Ahmed S (2004) The Cultural Politics of Emotion. Edinburgh: Edinburgh University Press.

Berlant L (1998) ed. Intimacy. Critical Inquiry 24/2 (Winter).

Berlant L (2008) The Female Complaint: The Unfinished Business of Sentimentality in American Culture. Durham and London: Duke University Press.

Berlant L (2011) Cruel Optimism. Durham and London: Duke University Press.

Breitwiesser S (2015) Andrea Fraser. Museum der Moderne, and Ostfildern: Hatje Cantz Verlag.

Butler J (2015) Notes Toward A Performative Theory of Assembly. Cambridge, MA: Harvard University Press.

Cardinal M (2000 [1975]) The Words to Say It: An Autobiographical Novel, trans. P Goodheart. London: The Women's Press.

Cvetkovich A (2012) Depression: A Public Feeling. Durham and London: Duke University Press.

Doolittle H [H.D.] (1974 [1956]) Tribute to Freud. New York: New Directions.

Fraser A (2003) Interview with Andrea Fraser by Yilmaz Dziewior. Andrea Fraser: Works 1984 to 2003. Hamburg: Dumont: 91-101.

Fraser A (2006) Why Does Fred Sandback's Work Make Me Cry? Grey Room (Winter): 3047.

Fraser A (2007) Psychoanalysis or Socioanalysis: Rereading Pierre Bourdieu. Texte Zur Kunst 68 December: 139-50.

Fraser A (2011) L'1\%, C'EST MOI. Texte zur Kunst , September , pp. 114-27

Fraser A (2012a) There's No Place Like Home. Andrea Fraser: Texte, Skripte, Transkripte/Texts, Scripts, Transcripts. Ed. C Cugini. Cologne: Museum Ludwig:144-61 
Fraser A (2012) Andrea Fraser in Conversation with Chris b, Tate Modern

http://www.tate.org.uk/context-comment/video/andrea-fraser-conversation-chris-dercon (accessed 10 February 2017)

Fraser A (2015) Performance or Enactment.

https://noreadingaftertheinternet.files.wordpress.com/2015/03/andrea-fraser-performance-orenactment.pdf (accessed 11 February 2017)

Fraser A (2016a) Act. In Terms of Performance.

http://intermsofperformance.site/keywords/act/andrea-fraser (accessed 11 February 2017).

Fraser A (2016b) Relational. In Terms of Performance.

http://intermsofperformance.site/keywords/relational/andrea-fraser (accessed 11 February 2017).

Fraser A (2016c) Andrea Fraser with Thyrza Nichols Goodeve The Brooklyn Rail. http://brooklynrail.org/2016/04/art/andrea-fraser-with-thyrza-nichols-goodeve (accessed 10 February 2017)

Freud S (2001/[1905/1901]) Fragment of An Analysis. In: The Standard Edition of the Complete Psychological Works of Sigmund Freud, Vol. VII, trans. J Strachey and A Freud. London: Vintage/The Hogarth Press and the Institute of Psychoanalysis, 3-112.

Freud S (2001/[1912]) The Dynamics of Transference. In: The Standard Edition of the Complete Psychological Works of Sigmund Freud, Vol. XII, trans. J Strachey and A Freud. London: Vintage/The Hogarth Press and the Institute of Psychoanalysis, 97-108.

Freud S (2001/[1914a]) Remembering, Repeating and Working-Through (Further Recommendations on the Technique of Psycho-analysis II. In: The Standard Edition of the Complete Psychological Works of Sigmund Freud, Vol. XII, trans. J Strachey and A Freud. London: Vintage/The Hogarth Press and the Institute of Psychoanalysis, 145-56.

Freud S (2001/[1914b]) Observations on Transference-Love (Further Recommdenations in the Technquie of Psycho-analysis III). In: The Standard Edition of the Complete Psychological Works of Sigmund Freud, Vol. XII, trans. J Strachey and A Freud. London: Vintage/The Hogarth Press and the Institute of Psychoanalysis, 157-71.

Freud S (2001 [1917/1915] Mourning and Melancholia. In: The Standard Edition of the Complete Psychological Works of Sigmund Freud, Vol. XI,V trans. J Strachey and A Freud. London: Vintage/The Hogarth Press and the Institute of Psychoanalysis, 237-60.

Freud S (2001 [1915-1917]) Anxiety. Lecture XXV, Introductory Lectures on Psychoanalysis. 
In: The Standard Edition of the Complete Psychological Works of Sigmund Freud, Vol. XVI, trans. J Strachey and A Freud. London: Vintage/The Hogarth Press and the Institute of Psychoanalysis, 392-411.

Freud S (2001 [1915-1917]) Transference. Lecture XXVII, Introductory Lectures on Psychoanalysis. In: The Standard Edition of the Complete Psychological Works of Sigmund Freud, Vol. XVI, trans. J Strachey and A Freud. London: Vintage/The Hogarth Press and the Institute of Psychoanalysis, 431-47.

Freud S (2001 [1926/1925]) Inhibitions, Symptoms and Anxiety. In: The Standard Edition of the Complete Psychological Works of Sigmund Freud, Vol. XX, trans. J Strachey and A Freud. London: Vintage/The Hogarth Press and the Institute of Psychoanalysis, 77-178.

Freud S (2001[1932/1933]) Anxiety and Instinctual Life, New introductory lectures on psychoanalysis. In: The Standard Edition of the Complete Psychological Works of Sigmund Freud, Vol. XXII, trans. J Strachey and A Freud. London: Vintage/The Hogarth Press and the Institute of Psychoanalysis, 81-111.

Freud S (2001[1937]) Analysis terminable and interminable. In: The Standard Edition of the Complete Psychological Works of Sigmund Freud, Vol. XXIII, trans. J Strachey and A Freud. London: Vintage/The Hogarth Press and the Institute of Psychoanalysis, 209-254.

Friedman B (2002) The Thief of Happiness: The Story of an Extraordinary Psychotherapy. Boston: Beacon Press.

Gunn D (2002) Wool-Gathering or How I Ended Analysis. New York: Taylor and Francis. Herman N (2001[1985]) My Kleinian Home: Into a New Millenium. London: Karnac.

Klein M (1960 [1932]) The Psychoanalysis of Children, trans. A Strachey. New York: Grove Press.

Klein M (1975), Love, Guilt and Reparation and Other Works 1921-1945 (London: Vintage, 1975).

Lacan J (2014) Anxiety: Book X, 1962-1963, ed J-A Miller, trans. A.R Price. London: Polity Press.

Laplanche J (1989 [1987]) New Foundations for Psychoanalysis, trans. D Macey. Oxford: Blackwell. 
Laplanche J (1999) Essays On Otherness, intro. J Fletcher. London and New York:

Routledge.

Lütticken S (2015) Andrea Fraser: Institutional Analysis. In Andrea Fraser, ed. S Breitwiesser. Salzburg: Museum der Moderne, and Ostfildern: Hatje Cantz Verlag.

Milner M (2002 [1934]) A Life of One’s Own. London: Virago.

Morra J (2008) The Work of Research: Remembering, Repeating and Working-through. In What is Research in the Visual Arts? Obsession, Archive, Encounter, eds. MA Holly, and M Smith. New Haven and Williamstown: Yale University Press and Sterling and Francine Clark Art Institute: 47-64.

Morra J (2012) Site-Responsivity, or Listening, Placing, and Saying It. In exhibition catalogue for Mieke Bal \& Michelle Williams Gamaker, and Renate Ferro's Saying It, curated by Joanne Morra at Freud Museum London. London: Occasional Papers, 2012: 9-16.

Morra J (2017a) On Use: Art Education and Psychoanalysis. In Fifty Years of Art and Objecthood: History, Impact, Critique, ed. with Alison Green, Journal of Visual Culture, April 2017: 56-73.

Morra J (2017b) Inside the Freud Museums: History, Memory and Site-Responsive Art. London: I.B. Tauris.

Nebrosky R J et. (2001) Short-Term Therapy for Long-Term Change. London: W. W. Norton \& Company, 2001.

Nin, A (1996 [1967] Fire from A Journal of Love: The Unpublished Unexpurgated Diary 19341937. London: Peter Owen.

Nixon M (2012) N. In Louise Bourgeois: The Return of the Repressed, ed. P Larratt-Smith. London: Violette Ltd: 85-100.

Nobus D (2000) Jacques Lacan and the Freudian Practice of Psychoanalysis. London and New York: Routledge.

Mitchell J (2012) The Sublime Jealousy of Louise Bourgeois. In Louise Bourgeois: The Return of the Repressed, ed. P Larratt-Smith. London: Violette Ltd: 47-70.

Pankejeff S (1989) The Wolf-Man and Sigmund Freud, ed. M Gardiner. London: Karnac. 
Perec G (1999 [1977]) The Scene of a Stratagem, Species of Spaces and Other Pieces, trans. and ed. J Sturrock. London: Penguin Books: 165-73.

Salecl R (2004) On Anxiety. London: Routledge.

Sandler J (1991) On Freud's 'Analysis Terminable and Interminable'. London: Karnac.

Sandler J et. al. (2007 [1973]) The Patient and the Analyst. London: Karnac.

Sedgwick EK (1999) A Dialogue on Love. Boston: Beacon Press.

Strachey J (1999 [[1934]) The Nature of the Therapeutic Action of Psycho-Analysis. Journal of Psychotherapeutic Practice Research 8/ Winter: 64-82. 